\title{
PRÁTICAS COERCITIVAS NA EDUCAÇÃO: O QUE DIZEM E O QUE FAZEM OS PROFESSORES
}

Rosina Forteski Glidden ${ }^{1}$

Ivan Gross ${ }^{2}$

\section{Resumo}

No contexto da formação do professor o uso de coerção é uma prática criticada, na prática o professor parece fazer uso de tais estratégias e desconhecer práticas alternativas de interação e ensino. O objetivo deste trabalho foi verificar a correspondência entre o relato e a prática acerca do uso de eventos coercitivos nas interações professor-aluno em quatro professoras dos anos iniciais do ensino público. Para tanto, foi utilizada uma metodologia combinada: questionário e observação direta. Os resultados apontaram a ocorrência de níveis de nãocorrespondência verbal/não-verbal em todas as participantes. Conclui-se pela necessidade, como aponta a literatura, de focalizar a análise dos comportamentos emitidos em relação ao que é relatado sobre a mesma realidade.

Palavras-chave: Psicologia; Educação; Correspondência Verbal e Não-verbal; Práticas Coercitivas

\section{INTRODUÇÃO}

O atual cenário da Educação vem demonstrando um fracasso cujos determinantes e condicionantes apresentam origens e fatores de manutenção diversos. De acordo com Skinner (1972), um sistema educacional é falho quando os alunos são levados a aprender pela ameaça.

\footnotetext{
${ }^{1}$ Psicóloga, Mestranda em Educação pela Universidade Federal do Paraná. Endereço: Rua Guilherme Pugsley, 1158, Água Verde, Curitiba, PR, Brasil. Cep: 80.620-000. Endereço eletrônico: rsforteski@gmail.com

${ }_{2}$ Psicólogo, Mestre em Educação pela Universidade Tuiuti do Paraná. Endereço: Rua Ubaldino do Amaral, 165, apto 408, Alto da Glória, Curitiba, PR, Brasil, Cep: 80.060-195. Endereço eletrônico: ivangross@ yahoo.com.br
} 
A predominância das técnicas coercitivas (menos ou mais sutis) denuncia um despreparo do professor para empreender técnicas alternativas eficazes.

Botomé (1994) critica a evolução da Educação, sugerindo que ela tem significado apenas uma troca das ferramentas de manipulação, e neste sentido permanecem, ainda, os alunos vivenciando o seu uso. Passou-se, portanto, da pregação moral para o uso do discurso e da instrução, com direito à cobrança de adesão e reprodução. Persistir na defesa dessas concepções e acreditar na eficiência de tais práticas mantêm os profissionais envolvidos com a Educação muito longe de aproveitar o arcabouço científico existente para melhorar o processo de ensino e aprendizagem. Também a evolução dos expedientes coercitivos modificou-se apenas no seu aspecto morfológico, passando de castigos físicos para a violência e manipulação psicológica (ARAGÃO, FREITAS, 2012; SKINNER, 1972).

Para um avanço qualitativo do sistema educacional Botomé (1994) sugere ser preciso avaliar a consistência entre teoria e prática, entre discurso retórico e atuações concretas do profissional educador frente aos desafios do cotidiano escolar. É necessário dirigir os esforços para a análise dos comportamentos emitidos em relação ao que foi dito sobre a mesma realidade. Ou seja, investigar quais os determinantes do fazer e do dizer docente.

Encontra-se nos trabalhos clássicos de Skinner (1972, 2000) e Sidman (1989), e mais atualmente nas contribuições de autores da Análise do Comportamento como Zanotto (2000, 2004), Viecili e Medeiros (2002), Pereira, Marinotti e Luna (2004), Hübner (2005), Rose (2005), Gioia e Fonai (2007) e Lorena e Cortegoso (2008), contundentes críticas e constatações dos prejuízos advindos da prática coercitiva na escola. Ademais, trabalhos como o de Ricci e Pereira (2006) denunciam possíveis incongruências entre o discurso e a prática docente.

Deste modo, supõe-se que a justificativa deste trabalho está na tentativa de disponibilizar bases científicas sobre a interação professor-aluno, com ênfase no uso da coerção, pelo viés da correspondência entre discurso e prática. Diante disto, foi elaborado como problema de pesquisa deste trabalho a seguinte questão: existe correspondência entre o discurso e a prática com relação ao uso de eventos coercitivos na interação professor-aluno em professores dos anos iniciais do sistema público de ensino? Para tanto, este trabalho objetivou verificar a correspondência entre o dizer e o fazer acerca do uso de eventos coercitivos na interação professor-aluno em professoras dos anos iniciais do sistema público de ensino. 


\section{PRÁTICAS COERCITIVAS: IMPLICAÇÕES E ALTERNATIVAS}

Eventos coercitivos e suas implicações foram extensamente estudados por Sidman Murray. Coerção, para Sidman (1989), se refere às classes de consequências que controlam o comportamento por reforçamento negativo, punição negativa ou punição positiva. Reforçamento positivo também é uma relação de controle, mas não é considerada coercitiva. Skinner (1972) lembra que o uso da coerção produz efeitos colaterais emocionais, dentre os quais é possível citar: medo, ansiedade, raiva, mágoa e ociosidade. Medo e ansiedade são implicações comuns dos comportamentos de fuga e esquiva. O contracontrole, que é o ataque ao agente manipulador dos eventos aversivos pelo indivíduo controlado, também se torna provável.

Muitas reformas foram realizadas em prol do abandono de punições corporais no ambiente escolar. No entanto, segundo Skinner (1972) e Aragão e Freitas (2012), as mudanças ocorridas no decorrer e em função destas reformas significaram meramente a alteração das ferramentas de coerção. Para Skinner (1972), hoje elas assumem formas punitivas não corporais como ridicularizarão, sarcasmo, críticas não construtivas, encarceramento, tarefas extras, isolamento, perda de privilégios, entre outras. Estes expedientes têm permitido que o professor puna sem marcar fisicamente o aluno. Sidman (1989) explica que embora a atual filosofia educacional condene o uso de expedientes coercitivos na escola, na sua prática o docente não utiliza o arcabouço teórico existente a respeito de metodologias educacionais não coercitivas. Os professores são informados das maleficências do seu uso, mas não sobre meios alternativos, assim, os métodos coercitivos tradicionais perduram através dos tempos.

A proposta alternativa sugerida pelos estudiosos da Análise do Comportamento faz referência à implementação do uso de reforço positivo ${ }^{3}$ nos processos de ensinoaprendizagem. Esta possibilidade precisa ser cuidadosamente explorada para manter os princípios democráticos, que são tão caros, também no campo da Educação (SKINNER, 1972, 2000).

\footnotetext{
${ }^{3}$ Pode-se conceituar reforço como "qualquer evento que quando apresentado aumenta a frequência de um comportamento e que quando retirado diminui a sua frequência" e punição como "qualquer evento que quando apresentado diminui a frequência de um comportamento e que quando retirado aumenta sua frequência" (TEIXEIRA JÚNIOR; SOUZA, 2006, p. 9).
} 
Para Zanotto (2000) o alerta para o caráter prejudicial do uso de técnicas coercitivas nos campos da Educação é um exemplo de um importante conhecimento produzido e difundido pela Análise do Comportamento e que pode ser relevante para o trabalho e para a formação do professor. A autora complementa ainda que, embora o efeito imediato na supressão do comportamento indesejado seja visível, o aspecto temporário do controle pela coerção é um fato que deve ser considerado pelo professor, pois proporciona um efeito reconfortante e por isso diminui a probabilidade de revisão de suas práticas.

A escola representa um conjunto de condições nas quais a criança se comporta para evitar ser punida, o reforço por comportamentos adequados e produtivos quando ocorre é fraco e inconsistente, a estas considerações somam-se ainda sentimentos de frustração e ansiedade (BANACO, 1993). Aragão e Freitas (2012) pontuam que os castigos utilizados pela escola antes e agora apenas mudaram na forma. De físicos passaram a ser psicológicos, no entanto, eles ainda são providos de violência e causam sofrimento a quem os recebe.

De acordo com Sidman (1989) o reforço negativo é o procedimento que prevalece no sistema educacional e o escasso reforço positivo disponível não é fornecido de forma contingente à aprendizagem do aluno. Ademais, o lema predominante ainda parece ser o da aprendizagem pela tentativa e erro. Este paradigma, no entanto, pode ser contraproducente e reforçar os comportamentos de erro do aluno.

Cumpre esclarecer que privar o aluno de reforço também é punir. Quando a evidência é de que o reforço não seja liberado a tendência é que os alunos apelem para a esquiva ou fuga e se isto também não for possível, a saída será o contra-ataque. Na febre dos contra-ataques, a violência segue uma escalada gradual deixando prejuízos por vezes irrecuperáveis, levando à desistência (a demissão do professor ou a evasão do aluno) ou ao totalitarismo de um dos lados (o despotismo do professor ou a anarquia estudantil) (SKINNER, 1972).

A formação docente precisa ser restaurada, segundo Viecili e Medeiros (2002) para que estes profissionais sejam capazes de identificar falhas em seus próprios comportamentos que podem estar pautados em expectativas e preconceitos em relação a alunos, ou classes de alunos, específicos. Pesquisa realizada pelos autores a respeito das implicações do uso da coerção em sala de aula relacionou entre as conclusões a existência de preconceitos dos professores no trato com alunos que apresentavam histórico de fracasso escolar e aos presumidos como bons alunos. Neste sentido, o conjunto de alunos que mais necessitava de suporte dos professores não o recebia, revelando um modelo de relação professor-aluno no 
qual o primeiro vem a estimular o fracasso do segundo. Assim, constataram os autores que práticas coercitivas constituem um mecanismo mantenedor de diferenças que não se resumem apenas aos desempenhos acadêmicos.

Conhecedores das implicações de um sistema educacional coercitivo, os estudiosos da Análise do Comportamento estão desde muito propondo o uso do reforço positivo como alternativa para a Educação. Como dizem Pereira, Marinotti e Luna (2004), uma análise baseada na teoria skinneriana focaria o planejamento de contingências positivas para aprendizagem, tanto para os professores, quanto para os alunos. Ainda que se admita que a escola e a própria sociedade são atualmente instituições aversivas, o que dificulta o empreendimento Behaviorista para o campo educacional. Também Sidman (1989) sugere o uso de reforçadores positivos na Educação, ressaltando que estes não são dificilmente identificados, tampouco representam novidade em sala de aula, uma vez que os professores melhor sucedidos vêm fazendo uso dele. No entanto, a prática majoritária consiste em galgar um tópico temático após outro, ignorando os alunos que acertam e punindo os que erram nas tarefas solicitadas. O melhor modo de empreender esta alternativa é propiciar ao aluno possibilidades de praticar o que aprendeu em teoria, neste processo o comportamento de aprender se torna reforçador por si mesmo, por prover acesso a outros reforçadores.

\section{CORRESPONDÊNCIA VERBAL E NÃO-VERBAL: O DIZER E O FAZER DOCENTE}

Estudos sobre correspondência verbal e não-verbal constituem uma linha específica de pesquisas realizadas analistas do comportamento e têm conseguido relevantes dados a respeito da congruência entre essas duas classes comportamentais (BECKERT, 2005). A correspondência entre as classes dizer e fazer é construída pela comunidade que designa determinadas relações entre palavras e eventos. Dizer e fazer são, respectivamente, comportamentos verbais e não-verbais. Entende-se por comportamento verbal uma relação de reciprocidade que envolve falante e ouvinte pelo efeito de modelagem de sua interação. Assim, além da necessidade de mediação, o comportamento verbal caracteriza-se pela liberação de reforço mútuo (CATANIA, 1999).

A literatura apresenta um conjunto de pesquisas que abordam a correspondência entre o dizer e o fazer que se utilizam, majoritariamente, de delineamentos experimentais, em ambientes não naturais. De acordo com Brino e De Rose (2006), tais empreendimentos científicos costumam focar duas classes de comportamentos específicas: a verbal e a não- 
verbal. Ainda, pode-se apontar outras duas subdivisões concernentes às pesquisas sobre correspondência: alguns pesquisadores direcionam seus intentos para o estudo dos níveis de controle do dizer enquanto antecedente do fazer e um segundo grupo se empenha em testar a fidedignidade do dizer que sucede o fazer, ou seja, do relato sobre o que foi feito. Em síntese, têm-se duas linhas principais de pesquisa sobre correspondência entre comportamento verbal e não-verbal: dizer-fazer e fazer-dizer.

O estudo de correspondências verbais demanda atenção a algumas premissas básicas para a compreensão sobre o relato verbal e a forma como cada indivíduo aprende a descrever a si próprio. Para Skinner (1974) é a comunidade verbal que ensina as pessoas como falar, o que inclui o comportamento de descrever a si mesmas e ao mundo que as circunda. É importante considerar ainda, conforme salienta Baum (1994), que o relato verbal é um comportamento operante e como tal sobrevive graças ao reforço que obtém. O reforço para este comportamento é dispensado de acordo com a discriminação de certas deixas públicas que antecedem sua emissão. Também o comportamento de lembrar, de acordo com Oliveira e Amaral (2009) depende do reforçamento social seletivo, sendo, portanto, uma construção mediada pelas interações socioculturais. Quando a comunidade teve acesso ao evento a ser lembrado, a tendência é que ela estabeleça ocasiões para a classe de respostas denominada "lembrar" de forma mais eficaz, pois neste caso o reforçamento seleciona mais discriminadamente os comportamentos emitidos.

No estudo realizado por Ribeiro (1989), pioneiro na área de correspondência verbal e não-verbal, a sequência abordada foi a fazer-dizer. $\mathrm{O}$ autor verificou a acuracidade do autorelato em oito crianças, quatro meninos e quatro meninas, com idades entre três e cinco anos. Foram testadas cinco condições experimentais, nas quais diferentes consequências verbais reforçadoras eram fornecidas para as crianças dependendo do conteúdo do relato. Na condição de linha de base (que não contou com consequências verbais) os níveis de correspondência constatados foram altos, após a introdução do reforço diferencial nas demais condições experimentais o nível de acuracidade mostrou-se baixo. Desta forma, o estudo mostrou que a fidelidade do relato foi comprometida pelo reforçamento diferencial fornecido pelo ouvinte.

O experimento de Baer e Detrich (1990) é outro clássico da área. Os autores abordaram a correspondência na sequência dizer-fazer com um grupo de crianças de quatro anos. Nos procedimentos experimentais observou-se que as crianças relatavam (por meio da escolha de uma imagem) a preferência por brincar com um brinquedo que após elas entrarem na sala, não era de fato o escolhido, revelando um auto-relato inacurado. As três opções das 
figuras apresentadas anteriormente para a escolha das crianças representavam brinquedos com os quais, em um momento anterior na sala, elas brincaram muito pouco. No entanto, a escolha de um dos brinquedos era condicional à entrada na sala das crianças. Para os autores, o relato que explicava tal condição teve função de mando para as crianças, pois sinalizava uma provável entrada na sala que elas já conheciam e que dispunha de uma variedade de brinquedos além dos apontados nas imagens.

Uma possível explicação para a discrepância entre o dizer e o fazer docente, conforme sugerem Ricci e Pereira (2006), pode ser a baixa acuracidade do comportamento de autoobservação dos indivíduos. O estudo das autoras efetuou uma análise da relação entre o dizer e o fazer de três professoras, os resultados da pesquisa apontaram não-correspondência no relato das participantes. As autoras, à guisa de conclusão, fazem alusão a alguns indícios de defasagem na habilidade do professor de se auto-observar nas situações dispostas no questionário. Porém, elas apontam que tais resultados precisam ser lidos com ressalvas, pois a situação natural pode ser diferente da situação imaginada por meio das perguntas do questionário. Por exemplo, ao imaginar sua resposta frente à determinada situação problema, o professor se auto-observa nesta situação em relação a alunos específicos, ou determinadas turmas, e não em relação a qualquer audiência discente.

Estudo realizado por Wechsler e Amaral (2009), visando fazer um levantamento das pesquisas sobre correspondência verbal e não-verbal já realizadas, sugere que estas produções são ainda pouco representativas quantitativamente, em particular no Brasil. Para os autores este fenômeno precisa ser mais aprofundado. É preciso considerar que a produção de artigos científicos na área é relativamente recente (desde 1961), o que aponta para a relevância da busca de uma compreensão mais profunda do fenômeno, o que demanda mais investimentos científicos nessa área por parte dos estudiosos do comportamento. Outra consideração importante levantada pelos autores se refere à predominância dos estudos com delineamentos experimentais sobre correspondência verbal, quando pesquisas descritivas poderiam trazer importantes contribuições a nível exploratório sobre o fenômeno.

\section{MÉTODO}

O presente estudo caracteriza-se como uma pesquisa exploratória, não-experimental, com objetivos descritivos, de caráter quali-quantitativo e com delineamento de sujeito único. De acordo com Andery (2010), o uso deste tipo de delineamento pela abordagem Behaviorista 
PRÁTICAS COERCITIVAS NA EDUCAÇÃO: O QUE DIZEM E O QUE FAZEM OS PROFESSORES

teve início em Skinner e surgiu como resposta a uma necessidade de respeitar as características mais básicas do comportamento como sua individualidade, interatividade e seu caráter processual e histórico.

Para a análise e interpretação dos dados foi exposta a distribuição das ocorrências dos eventos coercitivos utilizados por cada participante em situações hipotetizadas (questionário). Após efetuou-se a averiguação da distribuição de ocorrências dos eventos coercitivos utilizados por cada participante em situações reais (observação categorizada). Finalmente, verificou-se a correspondência entre os relatos verbais e os comportamentos emitidos em situação real relativos ao uso de eventos coercitivos de cada participante por meio da análise comparativa (por frequência) das categorias obtidas no questionário e das categorias obtidas na observação por registro de eventos.

\subsection{Participantes}

Participaram desta pesquisa quatro professoras regentes dos anos iniciais de uma escola do sistema público de ensino de uma cidade de médio porte do Norte de Santa Catarina. As professoras participaram da pesquisa mediante assinatura no Termo de Consentimento Livre e Esclarecido (TCLE), entregue após os devidos esclarecimentos sobre a natureza e os objetivos da pesquisa. A aprovação do Comitê de Ética Fameblu/Uniasselvi foi recebida em maio de 2012, processo $n^{\circ}$ 035/2012.

Com relação à idade das participantes a média constatada foi de 34,25 anos, com desvio padrão de 3,77. Quanto ao tempo experiência docente das participantes, D tinha 12 anos, B 5 anos e A e C 3 anos de docência.

Todas as participantes trabalhavam apenas no setor público de ensino. A e B trabalhavam apenas na escola pesquisada e C e D trabalhavam também em outra escola. C e D exerciam a função de professoras substitutas no momento da pesquisa.

\subsection{Local}

As observações se deram em sala de aula e a aplicação do questionário foi realizada em dois locais distintos, conforme disponibilidade das participantes, sendo eles: sala dos professores e sala de aula, quando os alunos estavam em Educação Física. 


\subsection{Coleta de dados}

Esta pesquisa fez uso de metodologia combinada: aplicação de questionário mais observação direta. O questionário respondeu à demanda de relato verbal, correspondendo ao comportamento de dizer do professor e as observações possibilitaram a coleta de dados referentes ao fazer docente.

Houve uma observação exploratória de registro cursivo, que antecedeu ao questionário e serviu de base para a emergência das categorias comportamentais e posterior construção do instrumento questionário. O questionário continha uma questão geral com oito subitens que solicitam informações sociodemográficas dos participantes; e 14 questões abertas que descreviam situações hipotéticas nas quais o professor deveria explicitar como agiria frente a elas em caso real, podendo ou não fazer uso de eventos coercitivos. Foram criadas duas questões para cada categoria comportamental. Ressalta-se que é possível identificar como eventos coercitivos aqueles que apresentam o uso de reforço negativo, punição positiva, punição negativa ou privação de reforço positivo (SIDMAN, 1989).

\subsection{Procedimentos para coleta de dados}

A coleta de dados foi realizada em cinco etapas, sendo: a) observação direta exploratória em sala para identificação de situações que apresentaram eventos coercitivos utilizados pelo professor; b) categorização destes comportamentos considerados coercitivos emitidos pelos professores com base no registro cursivo obtido na observação exploratória e no sistema de categorias proposto por Machado (1984) ${ }^{4}$; c) disposição das categorias elaboradas em formato de questionário. As categorias tomaram forma de perguntas abertas que descreviam situações problemáticas hipotéticas de sala de aula; d) aplicação do questionário como meio de obter relatos verbais descritivos quanto ao uso ou não de eventos coercitivos para resolução das situações hipotetizadas e e) observação direta em sala por registro de eventos com base nas categorias pertinentes às respostas obtidas de cada professor por meio do questionário.

\footnotetext{
${ }^{4}$ O sistema de categorias de Machado (1984) descreve o comportamento verbal de professores e alunos por meio do registro das sequências de verbalizações emitidas em sala de aula na sua interação, sua validade foi testada e estes resultados recomendam o seu uso em pesquisas futuras.
} 


\section{RESULTADOS}

\subsection{Emergência das categorias}

Participaram da observação exploratória para emergência das categorias quatro professoras dos anos iniciais de quatro diferentes anos, a média de observação foi de duas horas por professora. A técnica utilizada foi o registro cursivo de comportamentos verbais e não-verbais. Ao término das observações exploratórias as professoras foram convidadas a participar da pesquisa em si, que consistiu na aplicação do questionário seguida de observações por registro de categorias.

A seguir encontra-se descrito na Tabela 1 o sistema de categorias constituído com fins de classificar por evento os comportamentos considerados coercitivos emitidos pelo professor na sua interação com um aluno ou um grupo de alunos.

TABELA 1- Categorias comportamentais coercitivas do professor

\begin{tabular}{|c|c|c|}
\hline Categorias & Sigla & Descrição \\
\hline $\begin{array}{l}\text { Comportamento } \\
\text { Negligente }\end{array}$ & $\mathrm{CNE}$ & $\begin{array}{l}\text { Privar o aluno de reforço (atenção positiva, respostas, auxílio, } \\
\text { feedback), deixar a turma sem acompanhamento, não estar } \\
\text { disponível para os alunos. }\end{array}$ \\
\hline $\begin{array}{l}\text { Comportamento } \\
\text { Agressivo }\end{array}$ & CAG & $\begin{array}{l}\text { Proferir insultos (depreciar), recriminar energicamente ou } \\
\text { aumentar o volume de voz na direção de um aluno ou de um } \\
\text { grupo de alunos. }\end{array}$ \\
\hline $\begin{array}{l}\text { Comportamento } \\
\text { Cerceador }\end{array}$ & $\mathrm{CCE}$ & $\begin{array}{l}\text { Cerceamento da emissão de comportamentos interativos, } \\
\text { criativos, críticos ou que expressem aspectos da individualidade } \\
\text { do aluno. }\end{array}$ \\
\hline $\begin{array}{l}\text { Comportamento } \\
\text { Discriminante }\end{array}$ & CDI & $\begin{array}{l}\text { Direcionamento de atenção diferenciada negativa para alunos } \\
\text { com necessidades ou históricos específicos. }\end{array}$ \\
\hline $\begin{array}{l}\text { Comportamento } \\
\text { Expositivo }\end{array}$ & CEX & $\begin{array}{l}\text { Exposição, depreciação ou censura pública de dificuldades ou } \\
\text { respostas incorretas. Exigência inegociável de apresentação ou } \\
\text { relato verbal público de um aluno ou de um grupo de alunos. }\end{array}$ \\
\hline $\begin{array}{l}\text { Comportamento } \\
\text { Rígido }\end{array}$ & CRI & $\begin{array}{l}\text { Negar alteração da metodologia de trabalho segundo as } \\
\text { necessidades dos alunos, negar novas chances para os alunos } \\
\text { realizarem as tarefas. }\end{array}$ \\
\hline $\begin{array}{l}\text { Comportamento } \\
\text { Ameaçador }\end{array}$ & CAM & $\begin{array}{l}\text { Sugerir, avisar ou prometer punições e/ou retiradas de privilégios } \\
\text { a um aluno ou a um grupo de alunos. }\end{array}$ \\
\hline
\end{tabular}

Fonte: dados da própria pesquisa de campo, 2012. 


\subsection{Análise e interpretação dos resultados}

Os dados relativos à distribuição das ocorrências dos eventos coercitivos utilizados por cada participante em situações hipotetizadas (questionário), nas situações reais de sala (observação categorizada), e, por fim, a correspondência entre os relatos verbais e os comportamentos emitidos em situação real relativos ao uso de eventos coercitivos em uma análise de participante a participante estão apresentados na Tabela 2 a seguir.

TABELA 2 - Distribuição de ocorrências dos eventos coercitivos utilizados pela participante A relativas ao dizer e ao fazer e análise da correspondência entre as classes

\begin{tabular}{cccc}
\hline Categoria & Questionário & Observação & Correspondência \\
\hline CNE & 0 & 3 & 0 \\
CAG & 0 & 4 & 1 \\
CCE & 1 & 1 & 0 \\
CDI & 0 & 2 & 1 \\
CEX & 0 & 0 & 1 \\
CRI & 0 & 0 & 0 \\
CAM & 0 & 3 & 3 \\
Total & 1 & 13 & 3 \\
\hline
\end{tabular}

Fonte: dados da própria pesquisa de campo, 2012.

Dentre as situações hipotéticas disponibilizadas, a participante A optou pela utilização de eventos coercitivos que apresentaram os critérios de inclusão em 1 das 7 categorias, na categoria CCE (Comportamento Cerceador), totalizando 14,28\% em relação ao número total de categorias. Em situações reais ocorreu uso em 5 das 7 categorias, totalizando $71,42 \%$ em relação ao número total de categorias. Sendo que a categoria que apresentou maior número de ocorrências foi a CAG (Comportamento Agressivo), com 4 eventos.

Com relação à correspondência verbal/não-verbal acerca do uso de eventos coercitivos a participante A apresentou concordância em 3 categorias: CCE (Comportamento Cerceador), CEX (Comportamento Expositivo) e CRI (Comportamento Rígido), somando o total de 3 categorias dentre 7 , representando $42,86 \%$ em relação ao número total de categorias. Não houve correspondência nas 4 demais categorias (CNE, CAG, CDI e CAM), que representam $57,14 \%$ em relação ao número total de categorias. Percebe-se, pelo exposto, 
PRÁTICAS COERCITIVAS NA EDUCAÇÃO: O QUE DIZEM E O QUE FAZEM OS PROFESSORES

que o nível de não-correspondência é superior ao nível de correspondência com relação ao uso de eventos coercitivos pela participante A.

TABELA 3 - Distribuição de ocorrências dos eventos coercitivos utilizados pela participante B relativas ao dizer e ao fazer e análise da correspondência entre as classes

\begin{tabular}{rccc}
\hline Categoria & Questionário & Observação & Correspondência \\
\hline CNE & 0 & 0 & 1 \\
CAG & 0 & 7 & 0 \\
CCE & 0 & 0 & 1 \\
CDI & 0 & 2 & 0 \\
CEX & 0 & 2 & 0 \\
CRI & 0 & 0 & 1 \\
CAM & 1 & 0 & 0 \\
Total & 1 & 11 & 3 \\
\hline
\end{tabular}

Fonte: dados da própria pesquisa de campo, 2012.

A participante B optou pela utilização de eventos coercitivos que apresentaram os critérios de inclusão em 1 das 7 categorias, na categoria CAM (Comportamento Ameaçador), totalizando 14,28\% em relação ao número total de categorias. Em situações reais ocorreu uso em 3 das 7 categorias, totalizando 42,84\% em relação ao número total de categorias. Sendo que a categoria que apresentou maior número de ocorrências foi a CAG (Comportamento Agressivo), com 7 ocorrências.

Com relação à correspondência verbal/não-verbal acerca do uso de eventos coercitivos a participante B apresentou concordância em 3 categorias: CNE (Comportamento Negligente), CCE (Comportamento Cerceador) e CRI (Comportamento Rígido), somando 3 categorias dentre 7 , representando $42,86 \%$ em relação ao número total de categorias. Não houve correspondência nas 4 demais categorias (CAG, CDI, CEX e CAM), que representam $57,14 \%$ em relação ao número total de categorias. Percebe-se que também a participante B obteve um nível de não-correspondência superior ao nível de correspondência, com relação ao uso de eventos coercitivos. 
Tabela 4 - Distribuição de ocorrências dos eventos coercitivos utilizados pela participante C relativas ao dizer e ao fazer e análise da correspondência entre as classes

\begin{tabular}{cccc}
\hline Categoria & Questionário & Observação & Correspondência \\
\hline CNE & 0 & 4 & 0 \\
CAG & 0 & 6 & 0 \\
CCE & 0 & 5 & 0 \\
CDI & 0 & 11 & 0 \\
CEX & 0 & 7 & 0 \\
CRI & 0 & 1 & 1 \\
CAM & 1 & 2 & 1 \\
Total & 1 & 36 & 0
\end{tabular}

Fonte: dados da própria pesquisa de campo, 2012.

Dentre as situações hipotéticas disponibilizadas no questionário a participante $\mathrm{C}$ optou pela utilização de eventos coercitivos, que apresentaram os critérios de inclusão em 1 das 7 categorias, na categoria CAM (Comportamento Ameaçador), totalizando 14,28\% em relação ao número total de categorias. Em situações reais ocorreu uso em 7 das 7 categorias, ou seja, em $100 \%$ das categorias. Sendo que a categoria que apresentou maior número de ocorrências foi a CDI (Comportamento Discriminante), com uso de 11 eventos.

Com relação à correspondência verbal/não-verbal acerca do uso de eventos coercitivos a participante $\mathrm{C}$ apresentou concordância em apenas 1 categoria, CAM (Comportamento Ameaçador), dentre as 7 possíveis, representando 14,28\% em relação ao número total de categorias. Não houve correspondência nas 6 demais categorias (CNE, CAG, CCE, CDI, CEX e CRI), que representam $85,72 \%$ em relação ao número total de categorias. Assim, o nível de não-correspondência de C é consideravelmente superior ao nível de correspondência, com relação ao uso de eventos coercitivos.

TABELA 5 - Distribuição de ocorrências dos eventos coercitivos utilizados pela participante D relativas ao dizer e ao fazer e análise da correspondência entre as classes

\begin{tabular}{rccc} 
& e ao fazer e análise da correspondência entre as classes & & \\
\hline Categoria & Questionário & Observação & Correspondência \\
\hline CNE & 0 & 3 & 0 \\
CAG & 0 & 6 & 0 \\
CCE & 0 & 3 & 1
\end{tabular}




\begin{tabular}{cccc} 
CEX & 0 & 2 & 0 \\
CRI & 0 & 4 & 0 \\
CAM & 0 & 2 & 0 \\
Total & 1 & 25 & 1 \\
\hline
\end{tabular}

Fonte: dados da própria pesquisa de campo, 2012.

Dentre as situações hipotéticas a participante D optou pela utilização de eventos coercitivos, que apresentaram os critérios de inclusão em 1 das 7 categorias, na categoria CDI (Comportamento Discriminante), totalizando $14,28 \%$ em relação ao número total de categorias. Em situações reais houve ocorrência em 7 das 7 categorias, ou seja, em 100\% das categorias. Sendo que a categoria que apresentou maior número de ocorrências foi a CAG (Comportamento Agressivo), com 6 eventos.

Com relação à correspondência verbal/não-verbal acerca do uso de eventos coercitivos a participante D apresentou concordância em apenas 1 categoria, CDI (Comportamento Discriminante), dentre as 7 , representando $14,28 \%$ em relação ao número total de categorias. Não houve correspondência nas 6 demais categorias (CNE, CAG, CCE, CEX, CRI e CAM), que representam $85,72 \%$ em relação ao número total de categorias. Assim, também para a participante $\mathrm{D}$ o nível de não-correspondência é consideravelmente superior ao de correspondência.

As participantes C e D apresentaram os mais altos níveis de não-correspondência, $85,72 \%$ em contraposição a 14,28\% de correspondência. Cumpre ressaltar que ambas são professoras substitutas. Cabe ainda sugerir aqui uma leitura qualitativa em relação à participante C. No decorrer das observações essa participante relevou à pesquisadora sua insatisfação com a turma em geral, e também com alguns alunos específicos, fazendo constantes comparações com os alunos de sua outra turma, pertencentes à outra escola em que ela lecionava. C relatou ainda se sentir desconfortável entre os demais profissionais da escola. No intervalo, ela ficava em sua sala de aula, de modo a evitar a sala dos professores. Não é possível, dada a natureza descritiva e exploratória desse trabalho, relacionar essas questões com os altos níveis de não-correspondência, porém, sugere-se importante sua menção para uma compreensão global do fenômeno.

Após análise individual das participantes, algumas considerações são possíveis de se fazer em uma análise geral pela soma dos dados obtidos com as quatro participantes. Com 
relação às ocorrências do uso de eventos coercitivos apontados no questionário, pode-se observar uma prevalência de 50\% da categoria CAM (Comportamento Ameaçador), seguidos das categorias CCE (Comportamento Cerceador) e CDI (Comportamento Discriminante) com $25 \%$ de ocorrência cada.

Com relação às ocorrências do uso de eventos coercitivos coletados na observação categorizada é possível notar a prevalência dos eventos pertencentes à categoria CAG (Comportamento Agressivo) com 23 ocorrências, seguida da categoria CDI (Comportamento Discriminante) com 20 ocorrências. Segue-se a categoria CEX (Comportamento Expositivo) com 11 ocorrências. A categoria CNE (Comportamento Negligente) teve 10 ocorrências, a CCE (Comportamento Cerceador) apresentou 9 e 7 na CAM (Comportamento Ameaçador). A menor quantidade de ocorrências, 5, observa-se na categoria CRI (Comportamento Rígido).

\section{DISCUSSÃO}

Os dados que descrevem a quantidade de eventos coercitivos utilizados pelos professores não foram determinantes para a análise da correspondência. Cumpre esclarecer, pois, que o instrumento questionário não possibilita a quantificação de eventos, levantamento, no entanto, que se mostrou possível na observação categorizada. Os dados obtidos que se referem à quantidade de eventos coercitivos utilizados por cada professor levantam, porém, duas relevantes considerações, sendo a) a constatação de que alguns professores conseguem lançar mão de alternativas não-coercitivas com maior frequência que outros, e b) a constatação de que algumas categorias de eventos coercitivos têm maior uso que outras. Ainda que aprofundar estas questões não conste na proposta deste trabalho, espera-se que a sua emergência instigue outros empreendimentos investigativos que neste sentido.

Fica, após o término deste trabalho, no entanto, a angústia pelos dados obtidos por meio da categoria CDI (Comportamento Discriminante) que denuncia, em comparação às demais categorias (com exceção da categoria CAG, que teve 23 ocorrências (Comportamento Agressivo) e apresenta possibilidades mais amplas para preenchimento dos critérios de inclusão, o uso de um nível elevado de eventos (20) e é por isso merecedora de breve explanação. Uma análise qualitativa das interações com alunos percebidos negativamente em função de históricos específicos (hiperatividade, déficit de atenção, comportamento opositor, dificuldade de aprendizagem, déficit de habilidades sociais, entre outros) também sugere a existência de expectativas negativas do professor para quaisquer tarefas que lhes sejam 
PRÁTICAS COERCITIVAS NA EDUCAÇÃO: O QUE DIZEM E O QUE FAZEM OS PROFESSORES

solicitadas, mesmo que os alunos em questão não tenham manifestado qualquer indício de dificuldade ou de indisposição.

Esta espécie de fatalismo docente (que se apresenta em diferentes níveis para cada professor) frente ao comportamento destes alunos trabalha em detrimento da relação entre a díade e, certamente, em igual ou maior prejuízo para o desenvolvimento discente. Observa-se assim uma generalização do professor em relação às dificuldades dos alunos, pois neste processo prevalece o pressuposto de que tudo o que aquele aluno tiver de fazer, o fará com dificuldade, erroneamente ou com indisposição.

Este achado corrobora os resultados da pesquisa realizada por Viecili e Medeiros (2002) a respeito das implicações do uso da coerção em sala de aula. Nos resultados os autores relacionaram entre as conclusões a existência de preconceitos dos professores no trato com alunos que apresentavam histórico de fracasso escolar e aos presumidos como bons alunos. Neste sentido, o conjunto de alunos que mais necessitava de suporte dos professores não o recebia, revelando um modelo de relação professor-aluno no qual o primeiro vem a estimular o fracasso do segundo, e constatando que práticas coercitivas constituem um mecanismo mantenedor das diferenças.

Finalmente, e respondendo ao problema de pesquisa deste trabalho, todas as participantes apresentaram algum nível de não-correspondência. Sendo que os mais altos podem ser observados nas participantes $\mathrm{C}$ e $\mathrm{D}$, que apresentaram 85,72\% em contraposição a 14,28\% de correspondência. Também com níveis iguais, as participantes A e B apresentaram não-correspondência de 57,14\%, o que as deixa com um nível de correspondência de 42,86\%. Vale ressaltar, conforme demonstrado pelos resultados, que não se afirma existir uma dicotomia entre relatos não-correspondentes e relatos correspondentes, e sim uma predominância.

Os resultados obtidos pela efetivação deste trabalho apontam para a prevalência da não-correspondência do relato dos docentes com relação ao uso de eventos coercitivos no contexto de sala de aula, concordando assim com os resultados da pesquisa realizada por Ricci e Pereira (2006), que igualmente acusou a prevalência da não-correspondência entre o dizer e o fazer docente. Segundo as autoras, uma possível defasagem na habilidade de autoobservação frente a algumas demandas é determinante na baixa acuracidade do relato das professoras. A multiplicidade de variáveis presentes nas situações reais e ausentes nas situações hipotéticas do questionário também se apresenta como fator relevante para a mensuração da correspondência entre as classes de comportamentos docentes dizer e fazer. 
Cumpre ressaltar que a realidade de situações do contexto escolar atual não se limita a questões de ensino-aprendizagem, uma vez que outros processos de interação estão ocorrendo sem que sejam considerados oficialmente enquanto objetivos acadêmicos. Pode-se citar o confronto entre o cotidiano comum do professor e do aluno, que tem como base históricos de aprendizagem (sociais, culturais, morais etc) momentaneamente partilhados entre a díade, mas construídos separadamente e de maneira diferenciada. Assim, convém investigar o professor acerca de seu conceito próprio de "coerção". Propõe-se que algumas respostas emitidas, por exemplo, pertencentes à categoria Comportamento Cerceador (CCE), podem ser percebidas pelo docente enquanto questões de certo ou errado, moral ou imoral, se o professor considerar como objetivo de ensino o estabelecimento de práticas morais (com base na sua noção particular de moralidade, construída nas vicissitudes de sua história).

Ademais, conforme indica a teoria, uma formação majoritariamente verbalista atrai e convence por meio da dissipação de ideais promissores, que descrevem uma abordagem que considera e valoriza as habilidades e necessidades particulares de cada aluno. Frente ao seu cotidiano de trabalho, porém, o professor se depara com um contingente mais complexo de situações, e mais numeroso em demandas que vão desde avaliações qualitativas até resultados quantitativos que ainda são cobrados de maneira enfática nas diferentes instâncias de ensino.

Estes ideais promissores descrevem um cenário social certamente necessário e adequado. No entanto, o que se propõe revisar aqui não faz referência a que tipo de comportamentos se pretende ensinar, mas ao como se pretende ensinar tais comportamentos. É neste sentido que uma formação essencialmente verbalista se mostra insuficiente. A baixa acuracidade no relato verbal docente sugere indícios de defasagens na instância do fazer e tal déficit pode gerar a busca por alternativas punitivas perpetuadas por gerações que caracterizam as práticas coercitivas.

Sugere-se aqui a hipótese, que poderá subsidiar futuras pesquisas, de que uma formação com ênfase nas características citadas, por mais adequados que sejam os conteúdos dos discursos, não se mostra suficiente para munir o professor para o enfrentamento da complexidade de seu trabalho. A distância entre a emissão de um relato verbal e o uso factual de estratégias não-coercitivas em sala de aula é denunciada pelo baixo nível de correspondência encontrado. Neste sentido, faz-se possível compreender este fenômeno evitando um viés de "intencionalidade", e optando pelo viés da funcionalidade segundo o qual o uso de estratégias de ensino-aprendizagem com base na coerção apresenta como consequência uma série de efeitos que mantêm tal padrão operante fortemente estabelecido. 
PRÁTICAS COERCITIVAS NA EDUCAÇÃO: O QUE DIZEM E O QUE FAZEM OS PROFESSORES

Optar por estratégias de reforçamento positivo pode demandar repertórios mais elaborados por parte do docente e uma disposição de tempo e energia consideravelmente maior. Frente às tentativas frustradas de utilização de práticas não-aversivas o docente cede, pois de fato estratégias coercitivas se mostram mais eficientes em termos de imediaticidade de resultados.

Esta relação falha entre discurso e prática é descrita de forma crítica por Botomé (1994) que faz referência ao predomínio de uma racionalidade cínica e à defesa de uma realidade abstrata na qual a verdade está sempre em discursos. $\mathrm{O}$ autor salienta ainda que em uma formação extremamente verbalista a relação entre as palavras proferidas e a realidade presenciada não existe, é apenas suscitada pela eloquência da retórica empreendida. Neste tipo de noção, os discursos parecem indicar ações sem que haja relação real entre os processos de dizer e fazer. Os resultados aqui descritos sugerem ser necessário observar os diferentes tipos de reforçadores, punidores e, acima de tudo, os diferentes custos de resposta relacionados ao que se diz e ao que se faz.

O relato verbal, conforme descrito por Skinner (1974) é ensinado pela nossa comunidade verbal, incluindo os comportamentos autodescritivos. Tem-se ai, portanto, classes de comportamentos que são selecionadas - como todo operante - em função do seu valor de sobrevivência pela mediação social. Neste sentido, faz-se possível aprender quais características dos discursos serão reforçadas e quais serão punidas pela comunidade verbal. Os relatos emitidos pelas professoras no instrumento questionário (dizer) podem estar sob o controle de consequências reforçadoras que foram condicionadas socialmente acerca do uso de estratégias alternativas à coerção. Enquanto que os comportamentos em situação real podem estar sob controle das variáveis presentes no ambiente direto de sala de aula que vão desde o comportamento dos alunos até as variáveis mais particulares de cada professor.

\section{CONSIDERAÇÕES FINAIS}

A presente pesquisa analisou a existência da acuracidade entre o dizer e o fazer no relato de professoras dos anos iniciais acerca do uso de eventos coercitivos no seu trabalho. Pode-se constatar a não-correspondência entre relato e comportamento em todas as participantes dessa pesquisa. Todas relataram no questionário (dizer) uma frequência menor de uso de eventos coercitivos do que constatado na observação em sala (fazer). Considerando 
os eventos por categorias, na observação direta em sala, constatou-se emissão mais frequente dos comportamentos coercitivos agressivos e discriminantes.

$\mathrm{Na}$ análise considerou-se a constatação da não-correspondência em apenas uma categoria como suficiente para o estabelecimento da não-correspondência entre relato e prática do professor. No entanto, foram estabelecidos diferentes níveis de correspondência que, em função do delineamento de sujeito único utilizado, permitem inferir a particularidade do fenômeno da correspondência que pressupõe investigações individuais.

No contexto da formação do professor de anos iniciais o uso de ferramentas coercitivas é uma prática criticada, e no contexto da atuação do professor, seria esta uma prática evitada? Os resultados obtidos pela efetivação desta pesquisa sugerem que não. No entanto, esta não pode ser uma perspectiva absoluta e tão pouco reduzir, conforme já mencionado, a complexa causalidade do fenômeno de não-correspondência a meras questões de intencionalidade (de bases mentalistas), se desejamos, conforme defendido por Kubo e Botomé (2001) sair da esfera da problemática e alcançar a esfera da resolução de problemas nos campos da Educação. Afinal, cumpre notar a existência de níveis de correspondência constatados pelo trabalho, ainda que inferiores. Esta constatação convida a investigar as divergências e as aproximações das situações em que houve daquelas em que não houve correspondência verbal/não-verbal na busca pela elucidação dos determinantes e condicionantes que mantêm cada situação.

Embora tenham sido levantadas hipóteses - como uma formação docente com majoritariamente verbalista que não prepara eficientemente o professor para a complexidade de seu trabalho - com base na literatura que fundamentou este trabalho para o elevado nível de não-correspondência encontrado, respostas efetivas e sólidas devem ser perseguidas por meio de novas investigações. As características da interação professor-aluno são permeadas por variáveis de controle diversas e para entendê-las percebe-se a necessidade cada vez maior da proximidade do cientista com ambiente escolar.

Assim, diante dos achados dessa pesquisa, propõem-se o aprofundamento das relações anteriormente arroladas com a literatura que possam constituir hipóteses para pesquisas futuras que persigam as variáveis controladoras tanto da não-correspondência entre as duas classes comportamentais mencionadas quanto da perpetuação do uso de eventos coercitivos na escola.

\section{COERCION PRACTICES IN EDUCATION: WHAT THE TEACHERS SAY AND DO}




\begin{abstract}
In the context of teacher formation the use of coercion is criticized, but in practice the teacher seems to make use of such strategies and ignore alternatives for interaction and teaching practices. The objective of this work was checking the correspondence between the description and the practice of coercion events in the student-teacher interaction with four Elementary-School female teachers in a public school. To do that, a combined methodology was used: questionnaire and direct observation. The results showed the occurrence of a level of non-correspondence between what they say and what they do in all participants. The conclusion points to the need, as shown by the literature, to focus on the analysis of the behaviors in relation to what is reported in the same reality.
\end{abstract}

Keywords: Psychology; Education; Speaking And Non-Speaking Correspondence; Coercive Practices

\title{
PRÁCTICAS COERCITIVAS EN LA EDUCACIÓN: QUE DICEN Y HACEN LOS PROFESORES
}

\section{Resumen}

En el contexto de la formación del profesor, el uso de coerción es criticado; sin embargo, en su trabajo él parece hacer uso de este tipo de estrategia e ignorar así las prácticas alternativas de interacción y aprendizaje. El objetivo de este trabajo fue verificar la correspondencia entre el discurso y la práctica, acerca del uso de la coerción en las interacciones con alumnos en 4 profesores de los primeros grados de la educación pública. Por lo tanto, se utilizó un enfoque mixto usando: el cuestionario y la observación directa. Según los resultados se indica la existencia de un nivel de desajuste verbal/no verbal en todos los participantes. En conclusión, los resultados confirmaron la necesidad, como se ha señalado por la literatura, de centralizar el análisis de la conducta en relación con lo que se dice acerca de una misma realidad. 
Palabras clave: Psicología; Educación; Correspondencia Verbales Y No Verbales; Prácticas Coercitivas

\section{REFERÊNCIAS}

ANDERY, Maria Amalia Pie Abib. Métodos de pesquisa em análise do comportamento. Psicologia USP, v. 21, n. 2, p. 313-342, 2010.

ARAGÃO, M.; FREITAS, A. G. B. Práticas de castigos escolares: enlaces históricos entre normas e cotidiano. Conjectura, v.17, n.2, p. 17-36, 2012.

BAER, R. A.; DETRICH, R. Tacting and manding in correspondence training: effects of child selection of verbalization. Journal of the Experimental Analysis of Behavior, v. 1, n. 54, p. 23$30,1990$.

BANACO, Roberto Alves. Emoção e ação pedagógica na infância: contribuições da psicologia comportamental. Temas em Psicologia, v. 1, n. 3, p. 57-65, 1993.

BAUM, William. M. Compreender o Behaviorismo: ciência, comportamento e cultura. Porto Alegre: Artmed, 1999.

BECKERT, Marcelo Emílio. Correspondência verbal/não verbal: pesquisa básica e aplicações na clínica. Em: Abreu-Rodrigues, Josele; Ribeiro, Michela Rodrigues (Org). Análise do Comportamento: pesquisa, teoria e aplicação. Porto Alegre: Artmed, 2005.

BOTOMÉ, Silvio Paulo. Contemporaneidade, ciência, educação e... Verbalismo! Erechim: URI, 1994.

BRINO, A. L. F.; DE ROSE, J. C. Correspondência entre auto-relatos e desempenhos acadêmicos antecedentes em crianças com história de fracasso escolar. Revista Brasileira de Análise do Comportamento, v. 2, n. 1, p. 67-77, 2006.

CATANIA, Anthony Charles. Aprendizagem: comportamento, linguagem e cognição. 4. ed. (D. G. Souza, Trad.). Porto Alegre: Artes Médicas Sul, 1999.

GIOIA, P. S.; FONAI, A. C. V. A preparação do professor em análise do comportamento. Psicologia da Educação, n. 25, p. 179-190, dez, 2007.

HÜBNER, Maria Martha Costa. O Skinner que poucos conhecem: contribuições do autor para um mundo melhor, com ênfase na relação professor-aluno. Momento do Professor: revista de educação continuada, v. 4, n. 2, p. 44-49, 2005.

KUBO, O. M.; BOTOMÉ, S. P. Ensino-aprendizagem: uma interação entre dois processos comportamentais. Interação, v. 5, p.133-171, 2001. 
LORENA, A. B.; CORTEGOSO, A. L. Impacto de diferentes condições de ensino no preparo de agentes educativos. Revista Brasileira de Terapia Comportamental e Cognitiva, v. 10, n. 2 , p. 209-222, 2008.

MACHADO, Vera Lucia Sobral. Um sistema de categorias para a observação da interação verbal professor-aluno. Psicologia, v. 10, n. 1, p. 63-74, 1984.

OLIVEIRA, W.; AMARAL, V. L. A. R. O que se faz e o que se diz: auto-relatos emitidos por terapeutas comportamentais. Revista Brasileira de Terapia Cognitiva e Comportamental, v. 11, n. 1, p.132-153, 2009.

PEREIRA, M. E. M.; MARINOTTI, M.; LUNA, S. V. O compromisso do professor com a aprendizagem do aluno: contribuições da análise do comportamento. In: HÜBNER, Maria Martha Costa; MARINOTTI, Miriam. Análise do comportamento para a educação: contribuições recentes. Santo André: ESETec Editores Associados, 2004.

RIBEIRO, Antonio de Freitas. Correspondence in children's self report: tacting and manding aspects. Journal of the Experimental Analysis of Behavior, v.3, n. 51, p.361-367, 1989.

RICCI, L. S. V.; PEREIRA, M. E. M. Uma análise da relação entre o dizer e o fazer do professor. Psicologia da Educação, v. 23, p. 27-55, 2006.

ROSE, Júlio César de. Análise comportamental da aprendizagem de leitura e escrita. Revista Brasileira de Análise do Comportamento, v.1, n. 1, p. 29-50, 2005.

SIDMAN, Murray. Coerção e suas implicações. Campinas: Editorial Psy, 1995.

SKINNER, Burrhus Frederic. Tecnologia do ensino. São Paulo: Ed. Universidade de São Paulo, 1972.

. Sobre o Behaviorismo. São Paulo: Cultrix, 1994.

. Ciência e Comportamento Humano. 10. ed. São Paulo: Martins Fontes, 2000.

TEIXEIRA JÚNIOR, R. R.; SOUZA, M. A. O. Vocabulário de Análise do Comportamento. São Paulo: ESETec, 2006.

VIECILLI, J.; MEDEIROS, J. G. A coerção e suas implicações na relação professor-aluno. Psico-UFSC, v. 7, n. 2, p. 229-238, 2002.

ZANOTTO, Maria de Lourdes Bara. Formação de professores: a contribuição da análise do comportamento. São Paulo: EDUC, 2000.

ZANOTTO, Maria de Lourdes Bara. Subsídios da Análise do Comportamento para a formação de professores. In: Análise do comportamento para a educação: contribuições recentes. HÜBNER, Maria Martha Costa; MARINOTTI, Miriam. 1. ed. Santo André: ESETec Editores Associados, 2004. 
WECHSLER, A. M.; AMARAL, V. L. A. R. Correspondência verbal: um panorama nacional e internacional das publicações. Temas em Psicologia, v. 17, n. 2, p. 437-447, 2009.

Data de recebimento: 07/12/2013

Data de aceite: 06/01/2016 